\title{
A Rare Case of Multiple Primary Malignancy Diagnosed with Pancreatic Adenocarcinoma After Diffuse Large B Cell Lymphoma
}

\section{Diffüz Büyük B Hücreli Lenfoma Sonrası Pankreas Adenokarsinomu Tanısı Alan Nadir Multipl Primer Malignite Olgusu}

\author{
Ali Kutlucan ${ }^{1}$, Leyla Kutlucan², Esra Zeynep Coşkunoğlu ${ }^{3}$, Abdulkadir Baştürk ${ }^{4}$ \\ ${ }^{1}$ Başkent Üniversitesi Konya Uygulama ve Araştırma Merkezi, Hematoloji Bilim dalı, Konya, Türkiye \\ ${ }^{2}$ Konya Eğitim ve Araştırma Hastanesi, Anesteziyoloji ve Reanimasyon Kliniği, Konya, Türkiye \\ ${ }^{3}$ Başkent Üniversitesi Konya Uygulama ve Araştırma Merkezi, Tıbbi Patoloji Bilim dalı, Konya, Türkiye \\ ${ }^{4}$ Selçuk Üniversitesi Konya Uygulama ve Araştırma Merkezi, Hematoloji Bilim dalı, Konya, Türkiye
}

Dergiye Ulaşma Tarihi: 10.05.2019 Dergiye Kabul Tarihi: 08.07.2019 Doi: 10.5505/aot.2019.26879

\section{ÖZET}

Bir hastada birbiri ile ilişkisiz en az iki malignite görülmesi, 'Multipl Primer Maliginite' olarak tanımlanmaktadır. Diffüz büyük B hücreli lenfoma (DBBHL), NHL'ların en sık görülen histopatolojik alt tipidir. DBBHL ile birçok ikincil malignite bildirilmesine rağmen, DBBHL ile pankreas kanseri birlikteliği çok nadir bir klinik tablodur. Biz burada multipl primer malignite olarak, DBBHL remisyonu sonrası pankreas kanseri tanısı alan nadir bir olguyu sunduk. Altmış sekiz yaşında erkek hasta dış merkezde DBBHL tanısı alıp, sekiz kür kemoterapi sonrası remisyona girmiş. Kemoterapisi bittikten yaklaşı beş ay sonraki kontrollerinde kilo kaybı, karın ağrısı, iştahsızlık, genel durum bozukluğu şikayetleri ortaya çıkmış. Kliniğimize başvuran hastada pankreasta kitle ve karaciğerde metastatik lezyon saptandı. Karaciğerdeki lezyonun immünohistokimyasal bulguları adenokarsinom metaztazı olarak değerlendirildi. Klinik, patolojik, laboratuar bulguları ile pankreas kanseri tanısı konulmuştur. Primer malignitelerin tedavisi ve takibinde ek bulgular ortaya çıktı̆̆ında, yeni gelişen ikincil malignitelerin ayırıcı tanısının yapılması gerektiğini düşünüyoruz.

Anahtar Kelimeler: Diffüz büyük B hücreli lenfoma, pankreas adenokarsinomu, multipl primer maliginite

\begin{abstract}
The presence of at least two non-related malignancies in one patient is defined as Multiple Primer Maliginity. Diffuse large B-cell lymphoma (DLBCL) is the most common histopathological subtype of NHLs. Although many secondary malignancies have been reported with DLBCL, the association of DBBHL with pancreatic cancer is a very rare clinical entity. We report a rare case of multiple primary malignancies diagnosed as pancreatic cancer after remission of DBBHL. A 68-year-old man was diagnosed with DLBCL in another hospital and was in remission after eight cycles of chemotherapy. Approximately five months after the end of chemotherapy, weight loss, abdominal pain, loss of appetite, general state disorders appeared. The patient was admitted to our clinic with a mass in the pancreas and a metastatic lesion in the liver. Immunohistochemical findings of liver lesion were evaluated as adenocarcinoma metastasis. The patient was diagnosed with pancreatic cancer with clinical, pathological and laboratory findings. We think that differential diagnosis of newly developed secondary malignancies should be made when additional findings appear during the treatment and follow-up of primary malignancies.
\end{abstract}

Keywords: Diffuse large B cell lymphoma, pancreatic adenocarcinoma, multiple primary malignancy

\section{GíRiş}

Non-hodgkin lenfomalar (NHL) tüm malignitelerin yaklaşık \%4'ünü oluşturmakta olup, Diffüz büyük $\mathrm{B}$ hücreli lenfoma (DBBHL), NHL'ların en s1k görülen histopatolojik alt tipidir $(1,2)$. NHL'da hastaların \%50'sinden fazlasında hastalık ekstranodal bölgelerde ortaya çıkar ve özellikle mide, ince barsak başta olmak üzere gastrointestinal sistem en s1k tutulum bölgesidir (3). NHL'larda pankreas tutulumu da nadir bir durum olup, literatürdeki birçok vaka sunumunda; farklı klinik tablolarla başvuran hastalarda saptanan, pankreasın primer malign lenfoması olguları bildirilmiştir (4-6). 
Pankreatik kanserler, tan 1 ve tedavisinde yaşanan güçlükler nedeniyle ölüm oranı en yüksek olan kanser tiplerinden biri olup, bazen primer / sekonder pankreas kanseri ayırımı çok zor olabilmektedir (4).

'Multipl primer maliginite' bir hastada birbiri ile ilişkisiz en az iki malignite görülmesi olarak tanımlanmakta olup, DBBHL ile birçok ikincil malignite bildirilmesine rağmen, DBBHL ile pankreas kanseri birlikteliği çok nadir bir klinik tablodur $(7,8)$.

Biz burada, DBBHL tanıs1 alıp, kemoterapisi bittikten yaklaşık 5 ay sonra multipl primer maliginite olarak pankreas kanseri tanısı alan, nadir bir olguyu sunduk.

\section{OLGU SUNUMU}

68 yaşında erkek hasta kliniğimize kilo kaybı, karın ağrısı, iştahsızlık, genel durum bozukluğu şikayetleri ile başvurdu. Yaklaşık 14 ay önce kilo kaybı, boyunda şişlik nedeniyle dış merkezde tetkik edilen hastanın çekilen boyun manyetik rezonans (MR) görüntülemede, servikal zincirde ve submandibuler bölgede, büyüğü $3 \times 2 \mathrm{~cm}$ olan çok sayıda lenfadenopati saptanmış. Sağ servikal lenf nodundan eksizyonel biopsisi yapilan hastaya germinal tip DBBHL tanis1 konulmuş. Kemik iliği biopsisi normal olarak değerlendirilmiş. Rituksimab, siklofosfamid, adriamisin, vinkristin, prednizolon (R-CHOP) kemoterapisi başlanan hastada ilk kür sonras1 miyokart enfaktüsü gelişmesi nedeniyle kemoterapisi rituksimab, siklofosfamid, vinkristin, prednizolon (R-CVP) olarak devam edilmiş. Hastanın kilo kaybı ve diğer şikayetleri bu dönemde düzelmiş.

Kemoterapinin üçüncü ayında çekilen pozitron elektron tomografisinde (PET-CT); boyun, torax ve abdomen bölgelerinde anlamlı boyutta ve tutulumda lenfadenopati/kitle saptanmamış. Kemoterapinin dördüncü ayında yapilan abdominal ultrasonografisinde; karaciğer, dalak, pankreas, böbrek normal olarak değerlendirilmiş. Hastanın sekiz kürlük kemoterapisi tamamlandıktan sonra takibe alınmış. İki ay sonra yapılan tüm abdomen bilgisayarlı tomografisinde (BT); karaciğer, safra kesesi, pankreas, böbrekler normal saptanmış.
En son kontrolünden yaklaşık üç ay sonraki poliklinik kontrolünde belirgin kilo kaybı, genel durum bozukluğu olan hastada çekilen PET-CT'de; pankreas baş kesiminde $23 \times 28 \mathrm{~mm}$, artmış PDF tutulumu gösteren lenf bezi (SUVmax:8.63), karaciğer sağ lob segment 8 'de artmış PDF tutulumu gösteren lenf nodu (SUVmax:11.64) saptandığ1 raporlanmış. MRCP'de safra yolları ileri derecede dilate saptanmış. Hastaya tanı ve tedavi amaçlı batın operasyonu yapılmış. Patoloji raporunda; 'kronik kolesistit, reaktif lenf nodları, ağır displastik özellikte operasyon materyali' saptanmış.

$\mathrm{Bu}$ sonuçlarla kliniğimize başvuran hastada belirgin karın ağrısı ve kilo kaybı olmas1 nedeniyle ikinci bir malignite olabileceği düşünülerek abdomen BT ve tümör markerleri istendi. CA 19-9: $15239 \mathrm{U} / \mathrm{mL}$ (Normal: 0-37), CEA:9,91 ng/mL (Normal:3,1-5) saptandi. Abdominal BT raporu: 'Pankreas başı düzeyinde yaklaşık $4 \mathrm{x} 4$ $\mathrm{cm}$ boyutunda düzensiz lobule konturlu heterojen kontrast tutulumu gösteren solid kitle lezyonu izlenmiştir. Kitle ile duodenum arasındaki yağlı planlar kapanmıştır. Pankreasın diğer kısımları atrofik görünümde olup, pankreatik kanal geniş izlenmiştir. Karaciğer sağ lob anterior segmentte, yaklaşık 20x20 mm ebatta, portal fazda periferik kontrast tutulumu gösteren metastaz ile uyumlu kitle lezyonu izlendi. Mide duvarı diffüz olarak kalın izlenmektedir. Endoskopik değerlendirme ve biopsi önerilir. Duodenum duvarında da diffüz kalınlaşma izlenmiştir' şeklinde raporlandı (Resim 1). Endoskobik değerlendirmede maligniteyi düşündürür bulgu saptanmaması nedeniyle, karaciğerdeki metastatik lezyondan biopsi yapıldı. Patoloji sonucu da: 'Hazırlanan H\&E boyalı kesitlerde; karaciğer parankiminde desmoplastik stroma içinde adenokarsinom infiltrasyonu izlendi. İmmünohistokimyasal çalışmalarda tümörde CK7 ve CK 19 ile diffüz-kuvvetli boyanma görüldü. CK20 tek tük hücrede eksprese oldu. Glypican-3 ile tümörde boyanma izlenmedi. Hastanın yaşı ve cinsiyeti göz önünde bulundurularak ayırıcı tanı amaçlı yapılan ek immünohistokimyasal boyalardan PSA ve CDX2 ile tümörde boyanma görülmedi. Histomorfolojik bulgular ve immünohistokimyasal çalışma sonuçları öncelikle pankreatobiliyer sistem orijinli bir 
adenokarsinom metastazı olarak yorumland1' şeklinde raporlandı (Resim 2). Hastaya mevcut patolojik, radyolojik, laboratuar bulgular ile, diffüz büyük $\mathrm{B}$ hücreli lenfoma ile ilişkisiz multipl primer malignite olarak pankreas kanseri tanısı konuldu. Tedavi planı için hasta onkolojiye yönlendirildi.

Resim 1: A. Pankreas başında kitle, B. Mide duvar kalınlaşması, C. Metastatik kitle

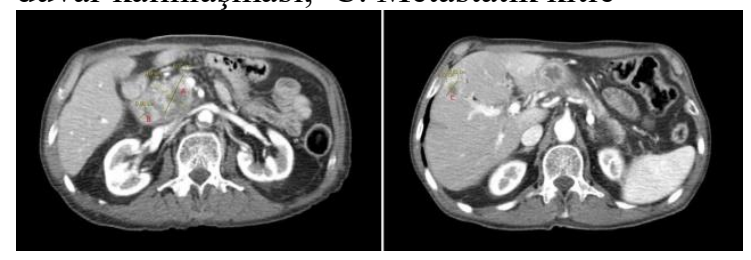

Resim 2: A. Karaciğer iğne biyopsi materyalinde adenokarsinom infiltrasyonu (H\&E 10x) B. Tümörde yaygın, kuvvetli CK7 pozitifliği (10x), C. Tümörde yaygın, kuvvetli CK19 pozitifliği (20x), D. Glypican 3 sağlam karaciğer parankimini boyamış ancak tümörde negatiftir (10x),

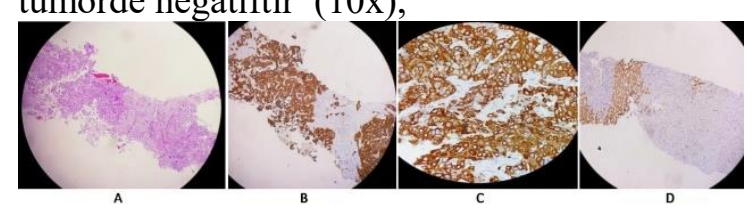

\section{TARTIŞMA}

Primer malignitelerin pankreası infiltre ettiği 'sekonder pankreas tümörleri' nadir bir durum olup, tüm pankreas kanserlerinin \%2-5'ini oluşturmaktadır. Sekonder pankreas tümörüne en s1k neden olan maligniteler ise; lenfoma, renal hücreli karsinom, akciğer kanserleri, meme ve kolorektal kanserlerdir (9).

NHL hastalarında yapılan geniş kapsamlı bir çalışmada; genel populasyona göre, 1.88 kat daha yüksek oranda ikinci malignite riski bildirilmiştir (10). $\mathrm{Bu}$ geniş kapsamlı çalışmada; mide, rektum ve larinksin sekonder malignite riski artışları belirgin olmasına rağmen, pankreas kanseri riskinde anlamlı artış bildirilmemiştir. Multipl primer maliginite olgu sunumlarında, DBBHL ile birçok sekonder malignite bildirilmesine rağmen (11), DBBHL ile pankreas kanseri birlikteliği sadece iki olgu sunumunda bildirilmiş. Myles ve arkadaşları, hematolojik olarak iki histiositik lenfoma ve bir KLL olgusu olmak üzere üç vakada, pankreas kanseri ile NHL birlikteliğini bildirmişlerdir (7). Whittington ve arkadaşları, pankreas kanseri sonras1 gelişen beş malignite olgusu bildirmiş, bu olgulardan bir tanesi de pankreas kanseri sonrası gelişen histiositik lenfomadır. Diğer dört malignite ise lenfoma dışındaki solid organ maligniteleridir (8). Bizim olgumuz ise, DBBHL tedavisi tamamlandıktan yaklaşık beş ay sonra gelişen pankreas kanseri olmasıyla bu vakadan ayrilmaktadır. Koyama ve arkadaşları, 75 yaşında bir erkek hasta otopsisinde, B-lenfoma ve pankreas adenokarsinomu birlikteliğini bildirmişlerdir (12). $\mathrm{Bu}$ olgunun DBBHL olup olmadığı ile ilgili veriye ulaşılamamıştır.

Sonuç olarak, primer malignitelerin tedavisi sirasında veya sonrasındaki takiplerde ek bulgular ortaya çıktığında ya da tedaviye yanıtsızlı durumlarında; multipl primer maligniteler düşünülmeli, hastanın ayrıntılı olarak değerlendirilmesi yapılarak, ikincil malignite açısından histolojik örneklemenin mutlaka akılda tutulması gerektiğini düşünmekteyiz.

Çıkar Çatışması Beyanı: Yazarlar çıkar çatışması olmadığını bildirmiş̧lerdir.

Finansal Destek: Bu çalışma her hangi bir fon tarafından desteklenmemiştir.

\section{REFERANSLAR}

1. Siegel R, Naishadham D and Jemal A: Cancer statistics. CA Cancer J Clin. 2013;63:11-30.

2. Stewart BW, Wild C. International Agency for Research on Cancer. World Health Organization. World cancer report 2014. International Agency for Research on Cancer; 2014 [cited 2017 May 8]. pp. 916. Available from: https://shop.iarc.fr/ products/wcr2014.

3. Kiresi DA, Kivrak AS, Ecirli S, Toy H: Secondary breast, pancreatic, and renal involvement with nonHodgkin's lymphoma: Imaging findings. Breast. 2006;15:106-10.

4. Blouhos K, Boulas KA, Paraskeva A, Kariotis I, Barettas N, Hatzigeorgiadis A. Obstructive jaundice as primary presentation of a stage IIENon-Hodgkin lymphoma: A decision making process betweenadvanced lymphoma and locally advanced/metastatic pancreaticadenocarcinoma. International Journal of Surgery Case Reports. 2018;44:226-9.

5. Ravindhran B, Prakash C, Govindharaj S, Bahnou NMS, Pavithra B. An Aggressive Primary Retroperitoneal Diffuse Larga B-Cell Lymphoma 
Mimicking a Pancreatic Neoplasm, Presenting as Duodenal Stenosis. J Clin Diagn Res. 2017;11(9):PD09-PD11.

6. $\mathrm{Yu} \mathrm{L}$, Chen Y, Xing L. Primary pancreatic lymphoma: two case reports and a literature review. Onco Targets Ther. 2017;10:1687-94.

7. Myles JL, Howard JM, Kim K, Dobelbower RR. Association of malignant lymphoma with pancreatic adenocarcinoma: a clinicopathologic study of three patients. Pancreas. 1991;6(2):249-52.

8. Whittington R, Moylan DJ, Dobelbower RR, Kramer S. Pancreatic tumours in patients with previous malignancy. Clin Radiol. 1982;33(3):297-9.
9. Mortenson MM, Katz MH, Tamm EP et al. Current diagnosis and management of unusual pancreatic tumors, Am. J. Surg. 2008;196:100-13.

10. Pirani M, Marcheselli R, Marcheselli L, Bari A, Federico M, Sacchi S: Risk for second malignancies in non-Hodgkin's lymphoma survivors: A meta-analysis. Ann Oncol. 2011;22:1845-58.

11. Tanba K, Chinen $\mathrm{Y}$, Uchiyama H, et al. Prognostic impact of a past or synchronous second cancer in diffuse large $\mathrm{B}$ cell lymphoma. Blood Cancer J. 2018;8(1):1.

12. Koyama S, Suzuki K, Komatsu Y, et al. Autopsy case of pancreatic carcinoma associated with Bcell derived lymphoma.

$$
\text { Gan }
$$

No 